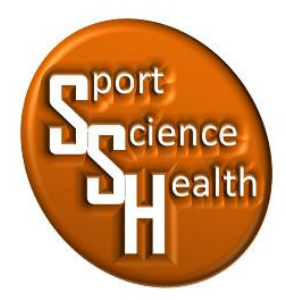

ISSN 2715-3886

\title{
Efektifitas Waktu Pelaksanaan Pembelajaran Pendidikan Jasmani, Olahraga dan Kesehatan di UPT Sekolah Dasar
}

\author{
Windah Tri Lestari ${ }^{1 *}$, Mashuri Eko Winarno² \\ 1,2Jurusan Pendidikan Jasmani, Kesehatan dan Rekreasi, Fakultas IImu Keolahragaan, \\ Universitas Negeri Malang, Jalan Semarang No 5, Malang, Jawa Timur, 65145, Indonesia \\ *Penulis koresponden: windahtrilestari6@gmail.com, 085806412282
}

Artikel diterima: 8 Januari 2020; direvisi: 14 September 2020; disetujui: 18 September 2020

\begin{abstract}
The purpose of this study was to determine the effectiveness of physical education learning time forsports and health at the SD Negeri Sukosewu, Gandusari District, Blitar Regency. This study shows that the effectiveness of the PJOK learning time has not been effective, it can be seen that the average time used is $99(71 \%)$. However, the systematic learning effectiveness was still not effective, the average result of the pre liminary activities was 16 $(11 \%)$, the core activities were $70(50 \%)$ while the closing activities were $13(9 \%)$. According to the criteria for teacher performance appraisal, the time effectiveness in core activities and closing activities is still too little time thathas been determined. To overcome this problem, it is necessary to start learning with the right time, use of time and modify the learning model in preliminary activities so that learning is more effective, and improve teacher performance.
\end{abstract}

Keyword: effectiveness, learning time

\begin{abstract}
Abstrak: Tujuan dari penelitian ini adalah untuk mengetahui efektifitas waktu pembelajaran pendidikan jasmani olahraga dan kesehatan yang bertempat di UPT SD Negeri Sukosewu Kecamatan Gandusari Kabupaten Blitar. Penelitian ini menunjukkan bahwa efektifitas waktu pembelajaran PJOK belum efektif, hal tersebut dapat dilihat dengan rata-rata waktu yang digunakan sebesar 99 (71\%) rata-rata tersebut menunjukkan dalam kategori baik sekali. Namun sistematika efektifitas pembelajaran masih belum efektif, hasil rata-rata pada kegiatan pendahuluan dengan total 16 (11\%), kegiatan inti sebesar 70 (50\%) sedangkan kegiatan penutup sebesar $13(9 \%)$. Menurut kriteria penilaian kinerja guru efektifitas waktu pada kegiatan inti dan ke giatan penutup masih terlalu sedikit waktu yang telah ditentukan. Untuk mengatasi permasalahan tersebut perlu memulai pembelajaran dengan waktu yang tepat, penggunaan waktu dan modifikasi model pembelajaran pada kegiatan pendahuluan agar pembelajaranlebih efektif, serta meningkatkan kinerja guru.
\end{abstract}

Kata kunci: efektifitas, waktu pembelajaran

\section{PENDAHULUAN}

Dalam proses pembelajaran guru lebih berperan sebagai motivator dan fasilitator agar peserta didik mau belajar. Guru sebagai tenaga professional bertugas merencanakan melaksanakan, menilai proses dan hasil pembelajaran, melakukan pembimbingan dan pelatihan, melakukan penlitian, membantu pengembangan dan 
pengelolaan program sekolah serta mengembangkan keprofesian secara kesinambungan (Abdul Rasid, 2013; Supadi, 2019; Suprihatin, 2015). Dalam pelaksanaan pembelajaran atau kegiatan belajar mengajar guru dituntut untuk dapat membelajarkan peserta didik sesuai dengan apa yang telah diprogramkan, sehingga benar-benar terarah sesuai dengan tujuan yang diharapkan (Norashid Othman \& Hamzah Md Omar, 2014; Purwanto et al., 2020; Widayati, 2014). Hal utama yang harus diperhatikan oleh guru adalah bagaimana cara mengelola kelas (classroom management) dengan sebaik-baiknya, serta mengimplementasikan strategi pembelajaran yang mengakomodasikan berbagai gaya belajar siswa (Mohammed Sani lbrahim, 2013; Mohd Khairuddin Abdullah, Khalid Hj Johari, Ag Yusof Ag Chuchu, \& Halimah Laji, 2014; Norashikin Abu Bakar, Ramli Basri, \& Fooi, 2015).

Pendidikan adalah serangkaian usaha yang dilakukan manusia untuk mengembangkan potensi dirinya melalui sebuah proses kegiatan yang disebut kegiatan pembelajaran. Tujuan dari pendidikan yaitu untuk meningkatkan ilmu dan pengetahuan serta mewujudkan generasi bangsa yang berilmu dan bermartabat. Dalam Undang-Undang Dasar Negara Republik Indonesia tahun 1945 pasal 31 ayat 3 "Pemerintah mengusahakan dan menyelenggarakan satu sistem pendidikan nasional yang meningkatkan keimanan dan ketaqwaan serta akhlak mulia dalam rangka mencerdaskan kehidupan bangsa yang diatur dalam undangundang". Pendidikan dilakukan secara bertahap dan terus menerus.

Pembelajaran memerlukan perencanaan untuk mencapai tujuan yang diharapkan oleh pendidik. Hal itu tertuang dalam Permendikbud No. 22 tahun 2016 dijelaskan bahwa Perencanaan pembelajaran dirancang dalam bentuk silabus yang kemudian dijadikan bahan atau acuan untuk membuat RPP yang mengacu pada standar isi. Perencanaan pembelajaran meliputi penyusunan RPP, penyiapan media dan sumber belajar, perangkat penilaian pembelajaran, dan skenario pembelajaran. Penyusunan RPP dan silabus disesuaikan pendekatan pembelajaran yang digunakan (Abdul Rahin Bin Hamdan et al., 2018; Alawiyah, 2015; Darmadi, 2015; Kirom, 2017; Norashid Bin Othman \& Hamzah Bin Md.Omar, 2014; Sutarmanto, 2015). Kegiatan belajar dilaksanakan secara sengaja dipersiapkan dalam bentuk perencanaan pengajaran, persiapan pengajaran ini sebagai kegiatan integral dari proses pembelajaran di sekolah (Alawiyah, 2015; Kartowagiran, 2015; Sukiman Saad, 2014).

\section{METODE}

Penelitian ini termasuk dalam jenis penelitian survei, selain itu pendekatan yang digunakan dalam penelitian ini adalah pendekatan deskriptif dan menggunakan metode penelitian kuantitatif. Pendekatan deskriptif bertujuan untuk mengetahui dan menilai efektifitas waktu yang digunakan dalam pembelajaran PJOK pada UPT SD Negeri Sukosewu. Metode kuantitatif bertujuan untuk mengetahui efektifitas waktu yang digunakan saat pembelajaran PJOK.

Penelitian bertempat di UPT SD Negeri Sukosewu Kecamatan Gandusari Kabupaten Blitar. Subjek penelitian merupakan responden atau pihak-pihak yang dijadikan sampel dalam sebuah penelitian. Subjek yang diambil dalam penelitian ini adalah 3 guru Pendidikan Jasmani Olahraga dan Kesehatan UPT SD Negeri Sukosewu dengan fokus penelitian efektifitas pelaksanaan pembelajaran.

Instrumen yang digunakan dalam penelitian ini adalah lembar observasi. Lembar observasi digunakan untuk mencatat semua kegiatan selama penelitian.

Analisis data merupakan metode untuk menganalisa serta mengolah data yang diperoleh setelah dilakukannya penelitian, tujuan menganalisis adalah untuk menyimpulkan data yang diperoleh secara deskriptif kualitatif dan kuantitatif. Teknik penelitian ini menggunakan analisis data metode statistik deskriptif kuantitatif dengan persentase. Statistik deskriptif adalah statistik yang digunakan untuk menganalisis data dengan cara mendeskripsikan atau menggambarkan data yang telah terkumpul sebagaimana adanya tampa bermaksud membuat kesimpulan yang berlaku untuk umum atau generalisasi (Jamshed, 2014; Tight, Symonds, \& Symonds, 2016) (Sugiyono, 2017:207).

Untuk menarik kesimpulan hasil presentase digunakan skla persentase berikut: 
Tabel 1. Konversi Hasil Perhitungan Presentase (Marvasti, 2018)

\begin{tabular}{llll}
\hline No & Skala Presentase & & Kategori Nilai \\
\hline 1 & $81 \%-100 \%$ & A & Predikat Hasil Evaluasi \\
2 & $61 \%-80 \%$ & B & Baik \\
3 & $41 \%-60 \%$ & C & Cukup \\
4 & $21 \%-40 \%$ & D & Kurang \\
5 & $0 \%-20 \%$ & E & Kurang Sekali \\
\hline
\end{tabular}

\section{HASIL}

Hasil penelitian dari efektivitas waktu pelaksanaan pembelajaran pendidikan jasmani olahraga dan kesehatan di MTs Negeri 2 Kediri akan dijelaskan sebagai berikut.

Efektifitas Waktu Pelaksanaan Pembelajaran Pendidikan Jasmani, Olahraga dan Kesehatan di UPT SD Negeri Sukosewu Kecamatan Gandusari Kabupaten Blitar.

Tabel 2. Data Hasil Penelitian Efektifitas Waktu Pelaksanaan Pembelajaran Pendidikan Jasmani, Olahraga dan Kesehatan di UPT SD Negeri Sukosewu Kecamatan Gandusari Kabupaten Blitar

\begin{tabular}{|c|c|c|c|c|c|c|c|c|c|}
\hline \multirow{2}{*}{$\begin{array}{l}\text { Alokasi Waktu } \\
\text { Kegiatan } \\
\text { Pembelajaran }\end{array}$} & \multirow{2}{*}{$\begin{array}{c}\text { Waktu } \\
\text { Maksimal }\end{array}$} & \multicolumn{2}{|c|}{ Guru I } & \multicolumn{2}{|c|}{ Guru II } & \multicolumn{2}{|c|}{ Guru III } & \multirow{2}{*}{ Rata-rata } & \multirow{2}{*}{$\%$} \\
\hline & & Menit & $\%$ & Menit & $\%$ & Menit & $\%$ & & \\
\hline Pendahuluan & 140 Menit & 16 & $11 \%$ & 15 & $11 \%$ & 16 & $11 \%$ & 16 & $11 \%$ \\
\hline Inti & 140 Menit & 70 & $50 \%$ & 70 & $50 \%$ & 70 & $50 \%$ & 70 & $50 \%$ \\
\hline Penutup & 140 Menit & 13 & $9 \%$ & 13 & $9 \%$ & 13 & $9 \%$ & 13 & $9 \%$ \\
\hline Jumlah & 140 Menit & 99 & $70 \%$ & 98 & $70 \%$ & 99 & $70 \%$ & 99 & $70 \%$ \\
\hline
\end{tabular}

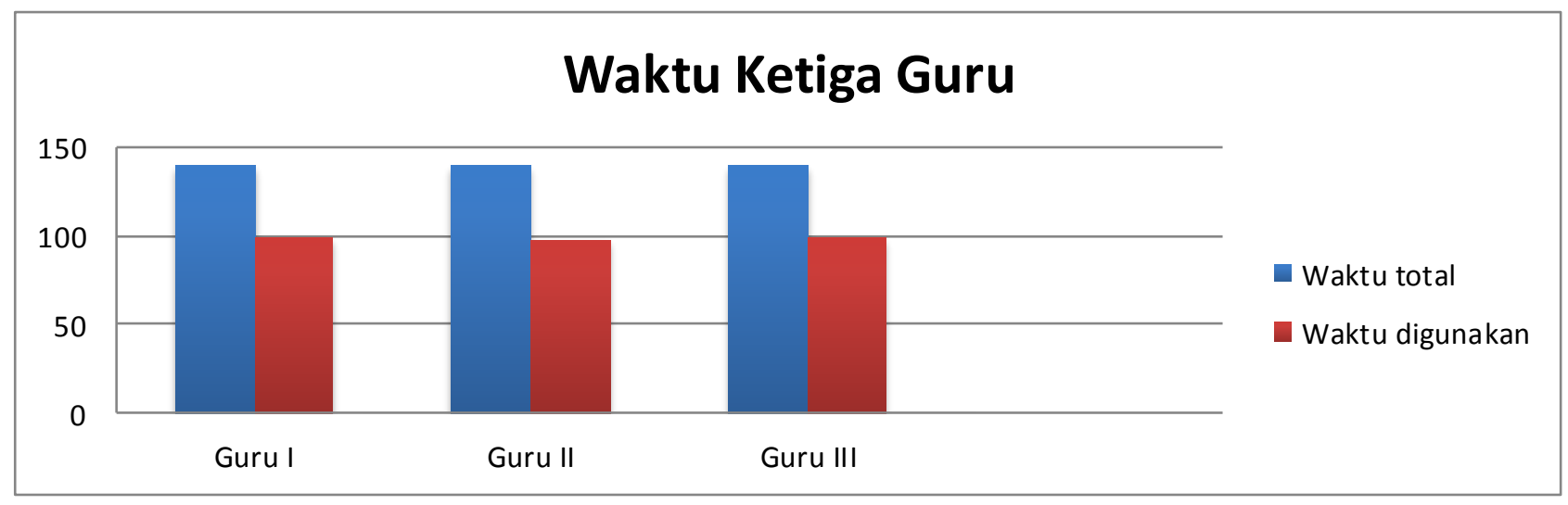

Gambar 1. Data Hasil Ketiga Guru

Berdasarkan hasil penelitian, dapat diketahui bahwa rata-rata waktu pembelajaran tiga guru UPT SD Negeri Sukosewu menggunakan waktu sebanyak 99 menit dengan persentase $70 \%$. Hasil penelitian diperoleh dengan cara menghitung total waktu dan rata-rata waktu pembelajaran ketiga guru. Setelah diperoleh data penelitian dapat dianalisis mengunakan analisis data kuantitatif untuk mengetahui rata-rata persentase waktu pembelajaran guru UPT SD Negeri Sukosewu Kecamatan Gandusari Kabupaten Blitar. 
Tabel 3. Data Hasil Penelitian Sistematika Efektivitas Waktu Pelaksanaan Pembelajaran Pendidikan Jasmani Olahraga dan Kesehatan di UPT SD Negeri Sukosewu Kecamatan Gandusari Kabupaten Blitar

\begin{tabular}{|c|c|c|c|c|c|c|c|c|c|}
\hline \multirow{2}{*}{$\begin{array}{l}\text { Alokasi Waktu } \\
\text { Kegiatan } \\
\text { Pembelajaran }\end{array}$} & \multirow{2}{*}{$\begin{array}{c}\text { Waktu } \\
\text { Maksimal }\end{array}$} & \multicolumn{2}{|c|}{ Guru I } & \multicolumn{2}{|c|}{ Guru II } & \multicolumn{2}{|c|}{ Guru III } & \multirow{2}{*}{ Rata-rata } & \multirow{2}{*}{$\%$} \\
\hline & & Menit & $\%$ & Menit & $\%$ & Menit & $\%$ & & \\
\hline Pendahuluan & 140 Menit & 16 & $11 \%$ & 15 & $11 \%$ & 16 & $11 \%$ & 16 & $11 \%$ \\
\hline Inti & 140 Menit & 70 & $50 \%$ & 70 & $50 \%$ & 70 & $50 \%$ & 70 & $50 \%$ \\
\hline Penutup & 140 Menit & 13 & $9 \%$ & 13 & $9 \%$ & 13 & $9 \%$ & 13 & $9 \%$ \\
\hline Jumlah & 140 Menit & 99 & $70 \%$ & 98 & $70 \%$ & 99 & $70 \%$ & 99 & $70 \%$ \\
\hline
\end{tabular}

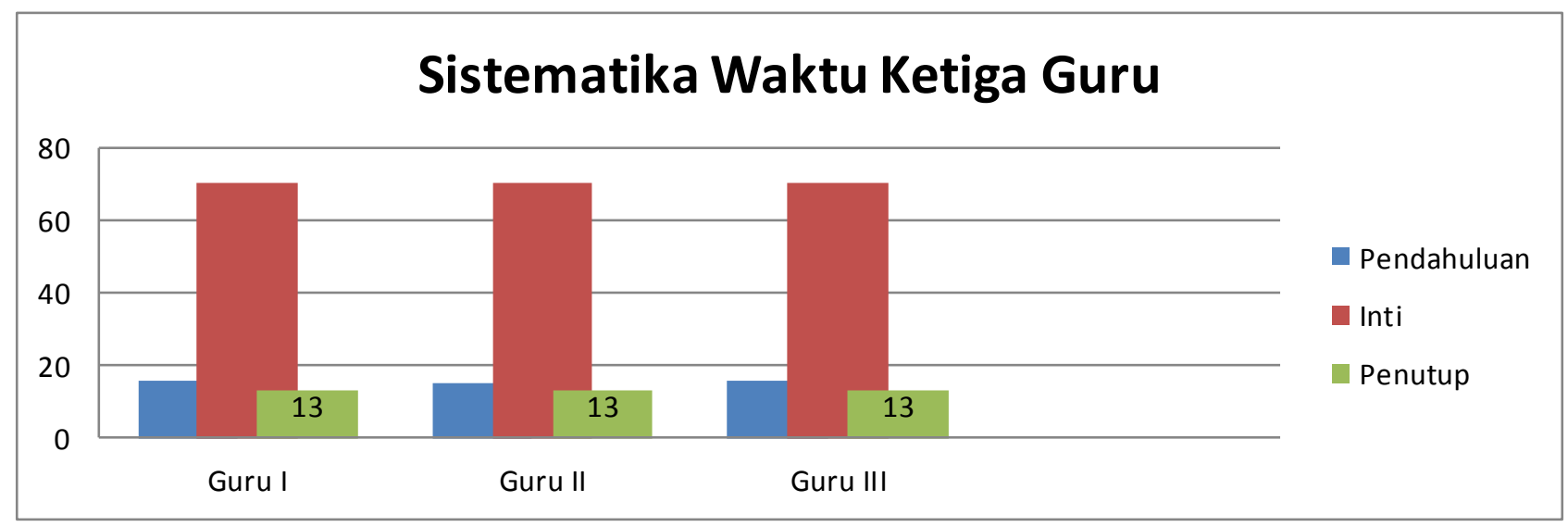

Gambar 2. Sistematika Data Hasil Ketiga

Berdasarkan tabel di atas, dapat diketahui bahwa pembelajaran masih belum efektif dikarenakan persentasi kegiatan pendahuluan, inti dan penutup tidak sesuai kriteria. Persentase pada kegiatan inti dan penutup melebihi kriteria, sedangkan persentase kegiatan inti kurang dari kriteria.

Tabel 4. Data Hasil Penelitian Guru Pertama tentang Efektivitas Waktu Pelaksanaan Pembelajaran Pendidikan Jasmani Olahraga dan Kesehatan di UPT SD Negeri Sukosewu 01Kecamatan Gandusari Kabupaten Blitar

\begin{tabular}{|c|c|c|c|c|c|c|c|c|c|c|}
\hline \multirow{2}{*}{$\begin{array}{l}\text { Alokasi Waktu } \\
\text { Kegiatan } \\
\text { Pembelajaran }\end{array}$} & \multicolumn{2}{|c|}{ Pertemuan 1} & \multicolumn{2}{|c|}{ Pertemuan 2} & \multicolumn{2}{|c|}{ Pertemuan 3} & \multicolumn{2}{|c|}{ Pertemuan 4} & \multirow{2}{*}{ Rata-rata } & \multirow{2}{*}{$\%$} \\
\hline & Menit & $\%$ & Menit & $\%$ & Menit & $\%$ & Menit & $\%$ & & \\
\hline \multicolumn{11}{|l|}{ Observer I } \\
\hline Pendahuluan & 17 & $12 \%$ & 15 & $11 \%$ & 16 & $11 \%$ & 16 & $11 \%$ & 16 & $11 \%$ \\
\hline Inti & 70 & $50 \%$ & 70 & $50 \%$ & 70 & $50 \%$ & 70 & $50 \%$ & 70 & $50 \%$ \\
\hline Penutup & 13 & $9 \%$ & 13 & $9 \%$ & 13 & $9 \%$ & 13 & $9 \%$ & 13 & $9 \%$ \\
\hline Jumlah & 100 & $71 \%$ & 98 & $70 \%$ & 99 & $71 \%$ & 99 & $71 \%$ & 99 & $71 \%$ \\
\hline \multicolumn{11}{|l|}{ Observer II } \\
\hline Pendahuluan & 17 & $12 \%$ & 16 & $11 \%$ & 15 & $11 \%$ & 16 & $11 \%$ & 16 & $11 \%$ \\
\hline Inti & 69 & $49 \%$ & 70 & $50 \%$ & 70 & $50 \%$ & 71 & $51 \%$ & 70 & $50 \%$ \\
\hline Penutup & 13 & $9 \%$ & 13 & $9 \%$ & 13 & $9 \%$ & 13 & $9 \%$ & 13 & $9 \%$ \\
\hline Jumlah & 99 & $71 \%$ & 100 & $71 \%$ & 100 & $71 \%$ & 101 & $72 \%$ & 99 & $71 \%$ \\
\hline
\end{tabular}

Pada hasil penelitian menunjukkan bahwa guru pertama mendapatkan kategori baik, hal itu karena persentase yang diperoleh $71 \%$ dan rata-rata waktu pembelajaran yang digunakan oleh guru pertama 99 menit. 
Tabel 5. Data Hasil Penelitian Guru Kedua tentang Efektifitas Waktu Pelaksanaan Pembelajaran Pendidikan Jasmani, Olahraga dan Kesehatan di UPT SD Negeri Sukosewu 03 Kecamatan Gandusari Kabupaten Blitar

\begin{tabular}{|c|c|c|c|c|c|c|c|c|c|c|}
\hline \multirow{2}{*}{$\begin{array}{c}\text { Alokasi Waktu } \\
\text { Kegiatan } \\
\text { Pembelajaran }\end{array}$} & \multicolumn{2}{|c|}{ Pertemuan 1} & \multicolumn{2}{|c|}{ Pertemuan 2} & \multicolumn{2}{|c|}{ Pertemuan 3} & \multicolumn{2}{|c|}{ Pertemuan 4} & \multirow{2}{*}{ Rata-rata } & \multirow{2}{*}{$\%$} \\
\hline & Menit & $\%$ & Menit & $\%$ & Menit & $\%$ & Menit & $\%$ & & \\
\hline \multicolumn{11}{|l|}{ Observer I } \\
\hline Pendahuluan & 15 & $11 \%$ & 15 & $11 \%$ & 15 & $11 \%$ & 15 & $11 \%$ & 15 & $11 \%$ \\
\hline Inti & 69 & $49 \%$ & 69 & $49 \%$ & 71 & $51 \%$ & 71 & $51 \%$ & 70 & $50 \%$ \\
\hline Penutup & 13 & $9 \%$ & 13 & $9 \%$ & 13 & $9 \%$ & 13 & $9 \%$ & 13 & $9 \%$ \\
\hline Jumlah & 97 & $69 \%$ & 97 & $69 \%$ & 99 & $71 \%$ & 99 & $71 \%$ & 98 & $70 \%$ \\
\hline \multicolumn{11}{|l|}{ Observer II } \\
\hline Pendahuluan & 15 & $11 \%$ & 15 & $11 \%$ & 15 & $11 \%$ & 15 & $11 \%$ & 15 & $11 \%$ \\
\hline Inti & 69 & $49 \%$ & 69 & $49 \%$ & 71 & $51 \%$ & 71 & $51 \%$ & 70 & $50 \%$ \\
\hline Penutup & 13 & $9 \%$ & 13 & $9 \%$ & 13 & $9 \%$ & 13 & $9 \%$ & 13 & $9 \%$ \\
\hline Jumlah & 97 & $69 \%$ & 97 & $69 \%$ & 99 & $71 \%$ & 99 & $71 \%$ & 98 & $70 \%$ \\
\hline
\end{tabular}

Pada hasil penelitian menunjukkan bahwa guru pertama mendapatkan kategori baik, hal itu karena persentase yang diperoleh $70 \%$ dan rata-rata waktu pembelajaran yang digunakan oleh guru pertama 98 menit.

Tabel 6. Data Hasil Penelitian Guru Ketiga tentang Efektifitas Waktu Pelaksanaan Pembelajaran Pendidikan Jasmani, Olahraga dan Kesehatan di UPT SD Negeri Sukosewu 04 Kecamatan Gandusari Kabupaten Blitar

\begin{tabular}{|c|c|c|c|c|c|c|c|c|c|c|}
\hline \multirow{2}{*}{$\begin{array}{l}\text { Alokasi Waktu } \\
\text { Kegiatan } \\
\text { Pembelajaran }\end{array}$} & \multicolumn{2}{|c|}{ Pertemuan 1} & \multicolumn{2}{|c|}{ Pertemuan 2} & \multicolumn{2}{|c|}{ Pertemuan 3} & \multicolumn{2}{|c|}{ Pertemuan 4} & \multirow{2}{*}{ Rata-rata } & \multirow{2}{*}{$\%$} \\
\hline & Menit & $\%$ & Menit & $\%$ & Menit & $\%$ & Menit & $\%$ & & \\
\hline \multicolumn{11}{|l|}{ Observer I } \\
\hline Pendahuluan & 16 & $11 \%$ & 17 & $12 \%$ & 16 & $11 \%$ & 15 & $11 \%$ & 16 & $11 \%$ \\
\hline Inti & 71 & $51 \%$ & 71 & $51 \%$ & 69 & $49 \%$ & 69 & $49 \%$ & 70 & $50 \%$ \\
\hline Penutup & 13 & $9 \%$ & 14 & $10 \%$ & 12 & $9 \%$ & 13 & $9 \%$ & 13 & $9 \%$ \\
\hline Jumlah & 100 & $71 \%$ & 102 & $73 \%$ & 97 & $69 \%$ & 97 & $69 \%$ & 99 & $71 \%$ \\
\hline \multicolumn{11}{|l|}{ Observer II } \\
\hline Pendahuluan & 16 & $11 \%$ & 17 & $12 \%$ & 16 & $11 \%$ & 15 & $11 \%$ & 16 & $11 \%$ \\
\hline Inti & 71 & $51 \%$ & 71 & $51 \%$ & 69 & $49 \%$ & 69 & $49 \%$ & 70 & $50 \%$ \\
\hline Penutup & 14 & $10 \%$ & 13 & $9 \%$ & 12 & $9 \%$ & 13 & $9 \%$ & 13 & $9 \%$ \\
\hline Jumlah & 101 & $72 \%$ & 101 & $72 \%$ & 97 & $69 \%$ & 97 & $69 \%$ & 99 & $71 \%$ \\
\hline
\end{tabular}

Pada hasil penelitian menunjukkan bahwa guru pertama mendapatkan kategori baik, hal itu karena persentase yang diperoleh $71 \%$ dan rata-rata waktu pembelajaran yang digunakan oleh guru pertama 99 menit.

Sistematika Waktu Pembelajaran Jasmani, Olahraga dan Kesehatan di UPT SD Negeri Sukosewu Kecamatan Gandusari Kabupaten Blitar.

Tabel 7. Sistematika Waktu Pembelajaran Jasmani, Olahraga dan Kesehatan di UPT SD Negeri Sukosewu Kecamatan Gandusari Kabupaten Blitar

\begin{tabular}{|c|c|c|c|c|c|c|c|c|c|}
\hline \multirow{2}{*}{$\begin{array}{l}\text { Alokasi Waktu } \\
\text { Kegiatan } \\
\text { Pembelajaran }\end{array}$} & \multirow{2}{*}{$\begin{array}{c}\text { Waktu } \\
\text { Maksimal }\end{array}$} & \multicolumn{2}{|c|}{ Guru I } & \multicolumn{2}{|c|}{ Guru II } & \multicolumn{2}{|c|}{ Guru III } & \multirow{2}{*}{ Rata-rata } & \multirow{2}{*}{$\%$} \\
\hline & & Menit & $\%$ & Menit & $\%$ & Menit & $\%$ & & \\
\hline Pendahuluan & 140 Menit & 16 & $11 \%$ & 15 & $11 \%$ & 16 & $11 \%$ & 16 & $11 \%$ \\
\hline Inti & 140 Menit & 70 & $50 \%$ & 70 & $50 \%$ & 70 & $50 \%$ & 70 & $50 \%$ \\
\hline Penutup & 140 Menit & 13 & $9 \%$ & 13 & $9 \%$ & 13 & $9 \%$ & 13 & $9 \%$ \\
\hline Jumlah & 140 Menit & 99 & $70 \%$ & 98 & $70 \%$ & 99 & $70 \%$ & 99 & $70 \%$ \\
\hline
\end{tabular}


Rata-rata waktu pada tabel di atas menunjukkan bahwa kegiatan pendahuluan sebesar 16 menit (11\%), kegiatan inti sebesar 70 menit (50\%), dan kegiatan penutup sebesar 13 menit $(9 \%)$.

\section{PEMBAHASAN}

Dalam pembelajaran interaksi peserta didik dengan guru maupun dengan siswa yang lain sangat penting. Semakin baik interaksi peserta didik dapat mempercepat proses belajar dan meningkatnya hasil belajar peserta didik, sehingga mencapai tujuan yang diharapkan. Efektivitas pembelajaran didasarkan dengan pengolahan proses pembelajaran yang dilakukan oleh guru kepada peserta didik. Berdasarkan penjelasan tersebut guru memiliki peranan penting dalam pembelajaran, untuk itu guru perlu meningkatkan atau melakukan proses pembelajaran yang lebih efektif dalam pelaksanaan dan waktu kegiatan pembelajaran. Penelitian ini bertujuan untuk mengetahui efektivitas waktu pembelajaran PJOK di UPT SD Negeri Sukosewu Kecamatan Gandusari Kabupaten Blitar, dalam penelitian yang dilakukan persentase total waktu guru sebesar $71 \%$ dengan waktu 99 menit, dari ketiga guru rata-rata persentase kegitan pendahuluan sebesar $11 \%$ dengan waktu 16 menit, kegiatan inti 50\% dengan waktu 70 menit, dan kegiatan penutup 9\% dengan waktu 13 menit.

Salah satu faktor yang menjadi keefektivan pembelajaran adalah kinerja seorang guru. Efektivitas pembelajaran itu sendiri memiliki criteria meliputi kemampuan guru, aktivitas peserta didik, hasil belajar demi tercapainya tujuan pembelajaran yang diinginkan (Susilo, 2013:3). Keterampilan atau kemampuan yang dimiliki guru untuk melaksanakan pembelajaran dapat mendukung keefektivan dalam pembelajaran, sehingga waktu yang digunakan dapat maksimal dan tepat. Penelitian Arif \& Hartati, Yuli (2016:188) menyatakan bahwa efektivitas berarti guru dan peserta didik dalam melaksanakan pembelajaran PJOK yang sudah direncanakan serta kemampuan untuk mencapai tujuan dan hasil yang ditetapkan. Efektivitas pembelajaran dapat meningkatkan jika pengolahan proses pembelajaran diatur dengan baik, efektivitas proses pembelajaran dapat dilihat dari proses dan hasil pembelajaran (Rohmawati, 2015).

\section{KESIMPULAN}

Dari hasil penelitian yang telah diperoleh, maka dapat disimpulkan bahwa pelaksanaan pembelajaran pendidikan jasmani olahraga dan kesehatan di UPT SD Negeri Sukosewu kurang efektif dengan waktu 99 menit $(71 \%)$. Dengan kata lain, bahwa penggunaan waktu pembelajaran pendidikan jasmani olahraga dan kesehatan tidak sesuai dengan pedoman yang telah ditentukan. Menurut penilaian pedoman guru kegiatan inti dan penutup sebaiknta tidak dikurangi $11 \%$ dari total waktu pembelajaran 140 menit dengan kisaran waktu 15 menit. Hal tersebut dibuktikan dengan rata-rata dari ketiga guru PJOK dengan total waktu 99 menit $(71 \%)$. Berdasarkan hasil penelitian, guru PJOK menggunakan waktu pembelajaran dengan rata-rata kegiatan pendahuluan 16 menit (11\%), kegiatan inti 70 menit (50\%), dan kegiatan penutup 13 menit (9\%). Pada pembelajaran tersebut guru terlalu sedikit menggunakan waktu pada kegiatan inti dan penutuBerdasarkan kesimpulan dari penelitian ini, maka saran yang dapat diberikan untu sekolah dan guru yaitu pada pelaksanaan pembelajaran PJOK di UPT SD Negeri Sukosewu Kecamatan Gandusari Kabupaten Blitar perlu diperbaiki waktu pembelajaran agar lebih efektif, dengan waktu pelaksanaan pembelajaran yang seharusnya. Serta guru PJOK member tahu kepada guru mata pelajaran lain untuk tidak menggunakan prasarana olahraga sewaktu masuk jam mata pelajaran PJOK, sehingga pembelajaran PJOK tidak terganggu.

\section{DAFTAR PUSTAKA}

Abdul Rahin Bin Hamdan, Ahmad Johari Bin Hj Sihes, Jamaluddin Bin Ramli, Rosliza Binti Hamzah, Bernama, Ezaleila Mustafa, S., ... Sonenthal, A. (2018). Media Sosial. Wuw.Moe.Gov.My.

Abdul Rasid, J. H. I. (2013). Pelaksanaan pembelajaran menyeronokkan dalam pengajaran dan pembelajaran bahasa melayu. Jurnal Pendidikan Bahasa Melayu.

Alawiyah, F. (2015). Kesiapan Guru dalam Implementasi Kurikulum 2013. Kajian Singkat.

Arif, M., \& Hartati, Yuli, S. C. 2016. Penerapan Modifikasi Permainan Bolavoli Terhadap Efektifitas Pembelajaran Pendidikan Jasmani, Olahraga, dan Kesehatan (Studi Pada Siswa Kelas VIII SMP Negeri 2 Candi Sidoarjo). 185-193. 
Darmadi, H. (2015). Tugas, Peran,Kompetensi, dan Tanggung Jawab Menjadi Guru Profesional. Jurnal Edukasi.

Jamshed, S. (2014). Qualitative research method-interviewing and observation. Journal of Basic and Clinical Pharmacy. https://doi.org/10.4103/0976-0105.141942

Kartowagiran, B. (2015). KINERJA GURU PROFESIONAL (GURU PASCA SERTIFIKASI). Jurnal Cakrawala Pendidikan. https://doi.org/10.21831/cp. బi3.4208

Kirom, A. (2017). Peran Guru Dan Peserta Didik Dalam Proses Pembelajaran Berbasis Multikultural. Al Murabbi.

Marvasti, A. (2018). Research methods. In The Cambridge Handbook of Social Problems. https://doi.org/10.1017/9781108656184.003

Mohammed Sani Ibrahim. (2013). Perana Guru Mata Pelajaran Dalam Mempertingkatkan Kualiti Pegajara Guru-guru. Jurnal Kurikulum \& Pengajara Asia Pasifik.

Mohd Khairuddin Abdullah, Khalid Hj Johari, Ag Yusof Ag Chuchu, \& Halimah Laji. (2014). Komunikasi guru dalam bilik darjah dan tingkah laku delinkuen murid sekolah menengah. Jurnal Pemikir Pendidikan.

Norashid Bin Othman, \& Hamzah Bin Md.Omar. (2014). Beban Tugas dan Motivasi Pengajaran Guru di Sekolah Menengah Daerah Ranau. Jurnal Pemikir Pendidikan (Journal for Educational Thinkers). https://doi.org/ISSN 1985-3637

Norashid Othman, \& Hamzah Md Omar. (2014). () Universiti Malaysia Sabah, 2014. Jurnal Pemikir Pendidikan.

Norashikin Abu Bakar, Ramli Basri, \& Fooi, F. S. (2015). Hubungan kepimpinan guru dengan pencapaian akademik pelajar. International Journal of Education and Training (InjET).

Purwanto, A., Pramono, R., Asbari, M., Santoso, P. B., Wijayanti, L. M., Choi, C. H., \& Putri, R. S. (2020). Studi Eksploratif Dampak Pandemi COVID-19 Terhadap Proses Pembelajaran Online di Sekolah Dasar. EduPsyCouns: Journal of Education, Psychology and Counseling.

Rohmawati, A. (2015). Efektivitas Pembelajaran. Jurnal Pendidikan Usia Dini.

Sugiyono. (2017). Metode Penelitian Pendidikan Pendekatan Kuantitatif Kualiatatif dan R\&D. Bandung: CV Alfabeta.

Sukiman Saad, N. S. S. dan M. U. D. (2014). Pengajaran kemahiran berfikir. Jernal Pendidikan.

Supadi. (2019). Kinerja Guru. In ljrm.

Suprihatin, S. (2015). Upaya Guru Dalam Meningkatkan Motivasi Belajar Siswa. PROMOSI (Jurnal Pendidikan Ekonomi). https://doi.org/10.24127/ja.ß3i1.144

Sutarmanto. (2015). Kompetensi Dan Profesionalisme Guru. Jurnal Visi Ilmu Pendiidkan.

Tight, M., Symonds, P., \& Symonds, P. M. (2016). The Case Study as a Research Method. In Case Studies. https://doi.org/10.4135/9781473915480.n2

Widayati, A. (2014). Penelitian Tindakan Kelas. Jurnal Pendidikan Akuntansi Indonesia. https://doi.org/10.21831/jpai.v6i1.1793 